\title{
R\&D for Emerging Infectious Diseases of Epidemic Potential: Sharing Risks and Benefits Through a New Coalition
}

\author{
Unni Gopinathan, Elizabeth Peacocke, Dimitrios Gouglas, Trygve Ottersen, \\ and John-Arne Røttingen
}

\begin{abstract}
The lack of effective vaccines for emerging infectious diseases (EID) of limited market potential, such as Chikungunya and Zika, poses a serious threat to human life and prosperity. Research and development $(R \& D)$ for new vaccines for EIDs faces two major challenges. The first is R\&D preparedness: that is, to advance EID vaccine candidates to the latest $R \& D$ stage possible during non-epidemic times, on the basis of any feasible safety or efficacy data. The second is R\&D response: that is, to test the clinical efficacy of vaccine candidates rapidly once an outbreak erupts. To overcome these challenges, the Coalition for Epidemic Preparedness Innovations (CEPI) was established in August 2016. Here, we explore why the realisation of CEPI's mission-preventing outbreaks of emerging infectious diseases from becoming humanitarian crises - is a global public good, and the crucial role R\&D preparedness and $R \& D$ response play in providing this good. We next examine why providing this global public good requires incentivising involvement and sharing risks with the private sector. Finally, we explore the potential for CEPI to be an agent mobilising shared responsibilities, including key factors that must be addressed in order for CEPI to demonstrate to governments that collective action is the preferred strategy for preventing future epidemics and strengthening global health security.
\end{abstract}

Keywords Research and development $\cdot$ CEPI $\cdot$ Neglected diseases $\cdot$ Intellectual property $\cdot$ Access to medicines

\section{Introduction}

In 2014-15 the world experienced the most severe Ebola epidemic in history. The epidemic hit the three West African states-Guinea, Liberia, and Sierra Leonethe hardest. In addition, Ebola was transmitted to several neighbouring states and, unlike in previous outbreaks, the world also observed the first confirmed cases of Ebola transmission outside Africa. The outbreak was unprecedented in length and

\footnotetext{
U. Gopinathan $(\bowtie) \cdot$ E. Peacocke $\cdot$ D. Gouglas $\cdot$ T. Ottersen · J.-A. Røttingen

University of Oslo, Oslo, Norway

e-mail: unni.gopinathan@gmail.com

(C) The Author(s) 2020

M. Eccleston-Turner and I. Brassington (eds.), Infectious Diseases in the New Millennium, International Library of Ethics, Law, and the New Medicine 82, https://doi.org/10.1007/978-3-030-39819-4_7
} 
size, and affected more people and more states than any other previous outbreaks of Ebola (Box 1). It is now widely accepted that the affected states and the global health system was unprepared for an Ebola epidemic of this magnitude. Assessments after the Ebola outbreak highlighted a number of factors affecting the response to the outbreak. ${ }^{1}$

Of these, we can highlight four major ones. Firstly, health systems in Guinea, Liberia, and Sierra Leone had never before encountered sustained transmission of Ebola, so health workers, communities, and policymakers had little or no experience dealing with the virus. A second major factor was that Guinea, Liberia, and Sierra Leone are all post-conflict states. As a consequence, these states had fragile and poorly-resourced health systems that were quickly overburdened by the epidemic, and low level of trust between the public and the governments when interventions to reduce the spread of Ebola had to be implemented. The third crucial factor was the slow and inefficient international response. The World Health Organisation (WHO) in particular was criticised for not declaring more quickly that the outbreak represented a public health emergency of international concern. ${ }^{2}$ Finally, a fourth area which received considerable attention was the lack of effective vaccines, therapeutics, and diagnostics to prevent the spread of Ebola. ${ }^{3}$ During and after the epidemic, it was recognised that $\mathrm{R} \& \mathrm{D}$ of effective biomedical tools were lacking for Ebola, as well as for other emerging infectious diseases (EIDs) with the potential to cause epidemics at a scale similar to Ebola. A consensus among post-Ebola assessments was the need for a more concerted global effort to strengthen R\&D for these diseases-with an emphasis on vaccines as an effective countermeasure against future epidemics. ${ }^{4}$

In response to these concerns, a new global health initiative-the Coalition for Epidemic Preparedness Innovations (CEPI) — was formally announced at the World Economic Forum in January 2017. ${ }^{5}$ The founding members of CEPI are the governments of Norway and India, the Gates Foundation, the Wellcome Trust, and the World Economic Forum. Motivating CEPI's establishment is the fact that clinical testing of Ebola vaccines proved successful during the epidemic, which in turn inspired the vision that "vaccines can prevent outbreaks of emerging infectious diseases from becoming humanitarian crises". 6 CEPI's corresponding mission is to "stimulate, finance, and co-ordinate vaccine development against emerging infectious diseases with epidemic potential, especially in cases where market incentives alone do not achieve this".?

In this chapter, we begin by examining whether the prevention of future epidemics of EIDs, which is CEPI's vision, represents a global public good. We then identify the main factors preventing the realisation of this good, and the rationale for establishing

\footnotetext{
${ }^{1}$ Gostin et al. (2016), Moon et al. (2017a).

${ }^{2}$ Kamradt-Scott (2016).

${ }^{3}$ Plotkin et al. (2015), Perkins et al. (2017), Bixler et al. (2017).

${ }^{4}$ Gostin and others (n 1); Plotkin, Mahmoud and Farrar, ibid.

${ }^{5}$ Brende et al. (2017).

${ }^{6}$ Røttingen et al. (2017).

${ }^{7}$ Ibid.
} 
CEPI. Next, we explore how CEPI will engage with private actors as part of its efforts to generate a global public good. We end by examining the potential for CEPI to demonstrate that collective action is the preferred strategy for preventing future epidemics.

\section{Box 1. The 2014-15 Ebola outbreak}

Retrospective identification of cases in this outbreak traced the index patient to be a 2-year old toddler in Guinea infected in December 2013. It took until March 2014 before an outbreak of Ebola was declared by national health authorities. Shortly after, Ebola was detected in neighbouring Liberia. On May 2016, Ebola had reached Sierra Leone, and over the next month the number of new cases per week escalated. Late in June, Doctors Without Borders called for increased international support-declaring that the epidemic was getting "out of control". In July, two infected US aid workers were evacuated from Liberia, Ebola was detected in Lagos in a patient who had travelled by air from Liberia, and Sierra Leone declared a state of emergency in order to quarantine the epicentres of the disease. This series of events ultimately compelled the WHO to declare the Ebola outbreak to be a public health emergency of international concern. An international response was triggered, which included an increased influx of financial resources and health personnel, building of treatment centres in Guinea, Liberia, and Sierra Leone, and the establishment of the UN Mission for Ebola Emergency Response (UNMEER).

Since its discovery in 1976, there had been twenty Ebola outbreaks prior to 2014. Previous outbreaks were confined to remote rural areas and contained within months, with the largest outbreak, in Uganda in 2000-01, having 425 cases and causing 223 deaths. In comparison, the 2014-15 outbreak spread to urban centres and the capital cities, lasted for over two years, and ultimately resulted in 28,616 cases (numbers from WHO's situation report as of June 10, 2016, including confirmed, probable, and reported cases) and 11,310 deathsmore than all previous outbreaks combined.

\section{Vaccines Against EIDs: A New Approach Needed to Provide a Global Public Good}

The classical, technical definition of a public good is a good that is both nonexcludable and non-rivalrous. ${ }^{8}$ A good is non-excludable when people cannot be prevented from enjoying its benefits once the good becomes available. When a good

\footnotetext{
${ }^{8}$ Samuelson $(1954,1955)$.
} 
is non-rival, the consumption of the good does not diminish the quantity available to others. Classic examples are the benefits of clean air and traffic lights.

What then qualifies as a global public good is interpreted differently in the vast literature on the subject. ${ }^{9}$ Discussing these differences in great detail is beyond the scope of this chapter. However, it is worth noting that a strict interpretation would only qualify goods that at all times, without exceptions, exhibit non-rivalry and non-excludability. ${ }^{10}$ An even stricter interpretation would additionally demand that everybody derive the same level of utility from the good. Successfully eradicating polio is a clear example of a good that is non-rivalrous and non-excludable. However, while eradication of polio eliminates the risk to everybody, it is reasonable to imply that populations living closer to sites of ongoing wild polio transmission (Afghanistan, Nigeria, and Pakistan) would value this good more than populations living in states where polio has long been eliminated.

More relaxed, and perhaps more useful, interpretations of what constitute global public goods can take two main forms. One where goods qualify as a global public good if the benefits in principle could reach populations across all states, without necessarily demanding that everyone derive the same measurable benefits. ${ }^{11} \mathrm{~A}$ second which includes goods that are subject to either excludability or rivalry, but where there is potential for specific policies to secure that these goods are non-rival and non-excludable. For example, as a result of patents, copyright, and paywalls, knowledge becomes excludable, and accordingly, knowledge is only a global public good insofar such restrictions are removed. Goods that incompletely exhibit non-rivalry or non-excludability are also referred to as impure public goods. ${ }^{12}$

It is also useful to be aware that a global public "good" refers both to directly providing utility, such as the benefits of making knowledge globally accessible, and reducing disutility by reducing harmful, cross-border spillover effects. The aforementioned examples of smallpox and polio eradication underscore the latter point. Other relevant examples are the effects of greenhouse gas emissions on climate change, or air pollution on clean air. The costs and harms of inaction on these issues exhibit both non-rivalry and non-excludability. It is also useful to distinguish between whether one considers the global public good to be the actual benefits (for example the prevention of future epidemics), or the infrastructure or systems put in place to produce these benefits (for example the International Health Regulations to reduce the cross-border risks of infectious diseases). In the context of this chapter, we consider the realisation of CEPI's mission — preventing outbreaks of emerging infectious diseases from becoming humanitarian crises - as the global public good. Numerous previous epidemics have demonstrated that if lack of capacity, resources or other reasons prevent a state from acting in time, the harms of an infectious disease may quickly be distributed to neighbouring states or to a different corner of the worlddemonstrating the non-excludable and non-rivalrous nature of the good. The Ebola

\footnotetext{
${ }^{9}$ Ress (2013), Kaul (2012), Morrissey et al. (2002).

${ }^{10}$ Morrissey, Willem te Velde and Hewitt, ibid.

${ }^{11}$ Kaul (n 9); Morrissey, Willem te Velde and Hewitt (n 9).

${ }^{12}$ Kaul (n 9); Morrissey, Willem te Velde and Hewitt (n 9).
} 
outbreak that started in 2014 is one example. Another striking example is the SARS outbreak in 2003-04. After emerging as an unknown disease in Guangdong in China in 2002, SARS had by May 2003 taken 41 lives in Canada (the only state outside Asia with fatal cases of SARS).

A different term applied to describe the global public good of mitigating the risk of infectious diseases is "global health security"-a term recognising that national borders do not stop the spread of infectious diseases, and that populations in all states can potentially be exposed to the risk if the spread in one part of the world is not prevented or controlled. ${ }^{13}$ In this context, vaccines play a crucial role. Vaccines can protect entire communities and states - either by reducing the incidence or eliminating an infectious disease from one part of the world, or as in the case of smallpox, eradicating it completely. Developing vaccines is a complex, costly, lengthy, and risky process. It is estimated that, on average, developing a vaccine from preclinical research requires over 10 years, with less than $10 \%$ probability of entering the market. ${ }^{14}$ Due to limited availability of publicly available data, precise estimates of vaccine development costs do not exist, but is suggested to be somewhere between $\$ 200 \mathrm{~m}$ and $\$ 500 \mathrm{~m} .{ }^{15}$ Depending on the complexity of the vaccine technology developed, the cost could be greater. Since vaccines are deployed to protect healthy individuals, strict regulatory requirements must be met to ensure safety, including continued monitoring for adverse effects once the vaccine has been introduced in immunisation programmes. In some cases, additional clinical trials are needed to disprove side effects. ${ }^{16}$ To recover the cost of constructing and maintaining vaccine and production facilities, vaccine manufacturers need to rely on economies of scale. For these reasons, large and predictable financial returns on investment are needed to attract pharmaceutical companies to invest in R\&D of vaccines. ${ }^{17}$ The market potential has been the main motivating factor for developing new vaccines (such as more recently developed vaccines against pneumonia and rotavirus) that protect against diseases also affecting populations in high-income states. Hence the lack of market potential is the main reason explaining why vaccines against EIDs are lacking.

At least two major factors explain why EIDs do not present themselves as an attractive investment. First, the emergence and re-emergence of these diseases is highly sporadic and confined to limited geographic areas in most cases. For example, prior to the Ebola outbreak in 2014-15, eleven of thirteen recent outbreaks had been confined to rural areas in either Uganda or the Democratic Republic of the Congo. ${ }^{18}$ Another example is SARS. Starting first in South-China, it spread to Singapore, Taiwan, and Canada, with 774 deaths reported globally. ${ }^{19}$ After China was declared free of SARS in May 2004, no new outbreaks have been detected.

\footnotetext{
${ }^{13}$ Commission on a Global Health Risk Framework for the Future (2016).

${ }^{14}$ Pronker et al. (2013).

${ }^{15}$ Serdobova and Kieny (2006).

${ }^{16}$ Offit (2005).

${ }^{17}$ Ibid.

${ }^{18} \mathrm{CDC}$ (2017).

${ }^{19}$ WHO (2017c).
} 
The sporadic epidemiology of these diseases creates uncertainty about how the vaccines will be used. Introduction into a state's routine immunisation programme or frequent use in mass vaccination campaigns are the most lucrative incentives for vaccine manufacturers to invest in R\&D of new vaccines; but for most EIDs, vaccines are unlikely (with a few potential exceptions) to be used in these ways. Instead, it is expected that vaccines will be stockpiled and reserved for emergency use or deployed in a few limited "hot zones". At the time of investments, uncertainty exists about volumes needed to stockpile and replenish a certain vaccine, and meeting stockpiling needs may be insufficient to recoup R\&D investments and earn profits.

A second important factor deterring participation in R\&D of EIDs is that clinical testing of a vaccine must be initiated in response to an outbreak of the disease. The risk exists that during an outbreak, clinical trials are delayed so much that an epidemic might be waning by the time the trials are initiated. If an insufficient number of events is observed, clinical trials will be unable to demonstrate conclusive evidence for efficacy. For example, in the midst of the Ebola outbreak in 2014-15, three phase III trials were initiated in Liberia, Sierra, and Guinea. Only one of these trials - the Ebola Ça Suffit! ring vaccination trial in Guinea-was able to successfully demonstrate efficacy (Box 2). The other two trials- the PREVAIL trial in Liberia and the STRIVE trial in Sierra Leone-were unable to determine vaccine efficacy due to a rapid decline in number of cases in these states. ${ }^{20}$

Reducing the time from the beginning of an outbreak until a safe vaccine is available for clinical evaluation requires, in addition to an available vaccine, agreement on scientifically sound, feasible, and ethically acceptable ways of testing vaccines during a public health emergency. ${ }^{21}$ The planning and execution of already expensive clinical trials therefore becomes more complicated, and implementation must occur under challenging conditions.

These factors explain why an effective vaccine for Ebola was unavailable prior to the 2015 epidemic, despite seven vaccines having been tested in monkeys with encouraging results prior to the epidemic. ${ }^{22}$ It is worth noting that the rVSV-ZEBOV Ebola vaccine was invented by researchers from the Public Health Agency of Canada in 2003, and had very promising animal results already in $2005 .^{23}$ The vaccine was later licensed to the biopharmaceutical company NewLink Genetics in 2010. Due to the lack of commercial incentives, further development and testing in healthy humans was not initiated until after the Ebola outbreak had intensified and high-income countries had begun to fly back health workers infected with Ebola. ${ }^{24}$

\footnotetext{
${ }^{20}$ Kennedy et al. (2016), CDC (2016).

${ }^{21}$ Folayan et al. (2016).

${ }^{22}$ Marzi and Feldmann (2014).

${ }^{23}$ Jones et al. (2005).

${ }^{24}$ Attaran and Nickerson (2014).
} 


\section{Box 2. Successful testing of an Ebola vaccine in Guinea}

During the WHO's first high-level Ebola vaccine meeting in October 2014, plans were drawn to test Ebola vaccine candidates in Sierra Leone and Liberia. Guinea, where the outbreak began, was initially thought to be too challenging a setting for assessing a vaccine. However, Guinea asked to be part of the Ebola vaccine development effort, and options for clinical trials designs for Guinea were discussed during an informal side meeting. Informed by data on safety, induction of potentially protective immune response, and availability of vaccine doses, the recombinant vesicular stomatitis virus Ebola vaccine (rVSVZEBOV) was selected as the vaccine candidate. This vaccine was originally developed by the Public Health Agency of Canada, and licensed to NewLink Genetics. To develop, manufacture, and distribute the vaccine candidate, Merck entered into an exclusive licensing arrangement with NewLink Genetics in November 2014. A consortium of the WHO, the Ministry of Health in Guinea, the Norwegian Institute of Public Health, and Médecins sans Frontières (MSF) lead the implementation of the trial, which also involved a trial team with representatives from a number of academic institutions. Phase 1 testing of the rVSV-ZEBOV vaccine candidate was planned prior to the October vaccine meeting, and was undertaken in Germany, Kenya, Gabon, and Switzerland over the next months. By January 2015, funding for an efficacy trial in Guinea was secured from a number of sources.

A novel clinical trial design - the 'ring vaccination trial'—was adopted. Under this design, direct contacts of a person newly diagnosed with Ebola, as well as contacts of contacts, constitute an epidemiologically defined ring. This ring is randomised to either an intervention group receiving immediate vaccination or a control group receiving delayed vaccination after 21 days (the incubation period in which $95 \%$ of EVD cases arise). The ring vaccination trial is based on smallpox eradication strategy. The efficacy trial in Guinea began already four months after the first discussions about a potential trial had been held. In July 2015, the consortium released results from an interim analysis demonstrating $100 \%$ vaccine efficacy. Final results published 1.5 years later confirmed these results. No cases of Ebola cases were recorded 10 days or more after vaccination among the 5837 people who received the vaccine. In comparison, there were 23 cases 10 days or more after vaccination among those who did not receive the vaccine.

Ultimately, the successful testing of this vaccine gave rise to two major lessons. Firstly, if phase 1 and phase 2 trials of the Ebola vaccine had been conducted prior to the epidemic, the vaccine could have been tested more quickly, probably as much as six months earlier, and even contributed to halting the spread of the epidemic. ${ }^{25}$ It was

\footnotetext{
${ }^{25}$ Røttingen and Godal (2015).
} 
therefore recognised that $\mathrm{R} \& \mathrm{D}$ preparedness - understood as innovation, advancement, and production of vaccine candidates that are stockpiled and ready for testing prior to an epidemic - needs strengthening. Secondly, testing of vaccines in response to an outbreak requires clarity in advance about issues such as manufacturing capacity to meet the needs of an epidemic, feasibility, scientific value, ethical acceptability of clinical trial designs, and a clear regulatory pathway towards approval. In other words, the R\&D response too needed to be strengthened (Box 3). Together, R\&D preparedness and $\mathrm{R} \& \mathrm{D}$ response represent areas that must be addressed to provide the global public good of preventing future epidemics.

\section{Box 3. $R \& D$ response-accelerating $R \& D$ and clinical evaluation of a vaccine in an outbreak}

Since phase 3 trials testing vaccine efficacy only can be initiated during an EID outbreak, CEPI will have to be part of a concerted effort with various stakeholders-including the WHO, governments, vaccine manufacturers, and global vaccine purchasers such as GAVI-to establish vaccine stockpiles that can be maintained and ready for potential emergency use. Even if stockpiles are established, the risk exists that clinical trials are delayed so much that an epidemic might be waning and almost over by the time the trials are initiated. As a consequence, clinical trials may not be able to demonstrate statistically significant effects. For example, during the recent Ebola outbreak, several vaccine trials were not completed due to the declining number of new Ebola cases at the time when trials were initiated. Reducing the time from the beginning of an outbreak until a safe vaccine is available for clinical evaluation therefore requires clarity on a number issues, such as agreement on manufacturing capacity, agreement on scientifically sound, feasible, and ethically acceptable ways of testing vaccines, a clear regulatory pathway in the states in which the vaccines are to be tested, and agreement on how clinical trials are to be coordinated and how data is to be shared.

What then explains the world's inability to achieve this? Part of the explanation is provided by the lack of market potential for EIDs, as described above. Fully explaining why no Ebola vaccine was available prior to 2015, or vaccines for other EIDs for that matter, requires also examining the public good characteristics of the benefits of $R \& D$ preparedness and $R \& D$ response. The classic challenge encountered by all public goods is that they are under-supplied since their two key properties-nonrivalry and non-excludability-prevent actors from capturing the full benefits from investing in them. Market mechanisms therefore frequently fail to provide public goods. A collective failure to provide the good results if no actor is willing to bear the costs of providing them. At the national level, governments and public authorities may use policies such as taxation, statutes, and regulations to provide public goods that are undersupplied by market forces. At the global level, no institutions exist to coerce national governments to contribute to the supply of global public goods, and 
nor does there exist a single global institution that is entrusted authority and financial resources to provide for such goods.

To fill this vacuum, a number of institutions has been established at the global level to organise and work out the details of international cooperation around specific issues such as environmental change, financial regulation, and global health R\&D - issues that exceed the capacity of national governments to address alone, and which require coordination and collaboration between public and private actors. ${ }^{26}$ The establishment of CEPI is born out of this recognition - that there is a need for a global institution to operate in the space between public and private actors in order to strengthen collaboration, coordination, and the sharing of risks. In the following two sections, we will examine how CEPI may mobilise and engage with these two groups of actors in order to strengthen $R \& D$ preparedness and $R \& D$ response.

\section{Incentivising the Private Sector to Strengthen Global Health Security}

Public goods and global public goods have in general been linked to the state as a provider and public financing as the main strategy for increasing provision. ${ }^{27} \mathrm{How}-$ ever, in many fields the private sector may play a crucial role for the provision of public goods given the right incentives from governments. In R\&D, factors necessitating the involvement of the private sector include their existing intellectual property and know-how, R\&D capabilities, manufacturing capacity, and systems for distributing vaccines. Incentivising private innovators to participate in partnerships to develop vaccines against EIDs will therefore prove vital to strengthening global health security. CEPI will fill a gap in the vaccine development pipeline (Fig. 1), and channel increased public and philanthropic financing in order to share the risk of R\&D.

Attracting private innovators to CEPI's public mission will require attention to two factors. Firstly, private innovators must perceive an acceptable level of risk of engaging in vaccine development against EIDs. ${ }^{28}$ CEPI's main risk-sharing strategy will be to invest directly in projects that move candidate vaccines from preclinical research through phase I and II trials, and thereby substantially reduce the total R\&D cost to private innovators. Secondly, private innovators can be incentivised to engage if there is commercial potential in addition to the public objectives. For some EIDs, a commercial market may exist for the vaccine in high-income states. For example, a vaccine may become profitable in the travel vaccines market in addition to protecting populations in states where an epidemic most likely will strike. Vaccine manufacturers may also see an opportunity to receive funding to develop vaccines on new platforms that may be later applied to develop vaccines with commercial

\footnotetext{
${ }^{26}$ Kaul (2013), Ötker-Robe (2014).

${ }^{27}$ Inge Kaul, 'Public Goods: Taking the Concept to the twenty-first Century' http://www.yorku.ca/ drache/talks/pdf/apd_kaulfin.pdf.

${ }^{28}$ Kettler and Towse (2002).
} 


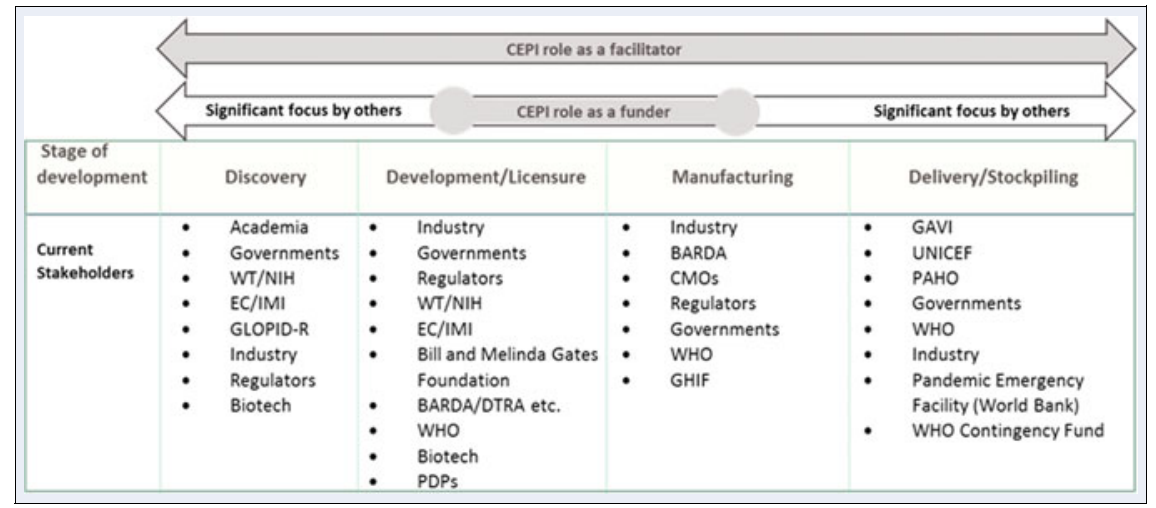

Fig. 1 CEPI's gap-filling role in vaccine development for EIDs

potential, in addition to the public objective funded by CEPI. In other cases where similar market opportunities are non-existent, a return on investment will depend on global financing bodies such as GAVI stepping in and procuring the vaccines at prices above the marginal cost of production.

From the public's point of view, investing public funds to reduce private innovators' economic risk of R\&D risks spending scarce public resources on unsuccessful projects. A complementary strategy for CEPI is therefore to implement some incentives that enhance the value of the EID vaccine market without exposing public funds to the risk of failure. This could be achieved by implementing "pull" incentives that reward outputs of $R \& D$ instead of paying for $R \& D$ inputs. ${ }^{29}$ One example is the milestone premium where innovators are rewarded for successfully completing predefined scientific milestones. At the time of writing, CEPI plans to implement a strategy where it only will provide additional funding for the next phase of vaccine development if milestones are met. If a project fails, no further investments are made and the project is discontinued.

In theory, CEPI could also experiment with larger milestone and end-stage prizes to motivate vaccine development. Such prizes have the benefit of making publicly financed incentives accessible for a broader range of actors without specifying the scientific route to success, which may be an advantage for vaccines in early-stage development. Over time, it can be expected that CEPI-in coordination with other funding entities-will implement a broader range of innovation incentives to motivate private investment in EID vaccines.

It should be recognised that CEPI plans in addition to make non-financial contributions to reduce uncertainties in EID vaccine development. This includes working with stakeholders to achieve a more predictable regulatory pathway, optimising coordination and data sharing, and facilitating interaction with regulatory authorities of states where the vaccines are likely to be tested. Over the past 15 years, a number of

\footnotetext{
${ }^{29}$ Kremer and Glennerster (2016).
} 
different public-private partnerships such as the Drugs for Neglected Disease initiative and the Medicines for Malaria Venture have been established to address market failures affecting R\&D for neglected diseases. ${ }^{30}$ These too have pooled private and public resources to pursue publicly defined objectives, and to achieve mutually beneficial goals. ${ }^{31}$ Examining the experience and lessons from these initiatives suggest three broader areas where CEPI could make valuable contributions.

The first is diversifying the range of actors engaged with vaccine development against EIDs, and strengthening global R\&D capacity in this area. By implementing the incentives described above, it is reasonable to expect that multinational vaccine manufacturers will bring crucial know-how, manufacturing facilities, and platform technologies to the table. Leading multinational vaccine manufacturers have already actively been engaged as part of CEPI's establishment. ${ }^{32}$ Three additional groups could potentially add value to CEPI's mission. The first group is small to mediumsized commercial vaccine companies, biotechs and contract manufacturing organisations (CMOs). The second group is the members of the vaccine-industry alliance The Developing Countries Vaccine Manufacturers' Network (DCVMN), who have an increasingly important role in meeting the global demand for vaccines as well as developing novel ones. ${ }^{33}$ A testament to their role is that of 2.4 billion doses of vaccines procured by UNICEF in $2015,60 \%$ were sourced from DCVM. ${ }^{34}$ Finally, CEPI can also work with existing government-run and publicly funded non-profit organisations that have know-how and expertise on vaccine development and manufacturing capabilities. These have traditionally been set up to focus on meeting national public health needs. By engaging with CEPI, their expertise could be leveraged to meet global needs. One concrete example is the Centers for Innovation in Advanced Development and Manufacturing. This centre was set up as a privatepublic private partnership with the U.S. Department of Health and Human Services Biomedical Advances Research and Development Authority (BARDA). It is part of the US national strategy to strengthen manufacturing capacity to respond to various biological threats including novel and previously unrecognised infectious diseases, as well as chemical, biological, radiological and nuclear threats. ${ }^{35}$ BARDA suggested during the establishment of CEPI that it could work with CEPI's partners to produce vaccines using vaccine platforms supported by the Center. ${ }^{36}$

A second area where CEPI can meaningfully contribute is in demonstrating that coordination and collaboration between public and private actors motivated by a public objective can optimise the use of available knowledge and intellectual property, reduce duplication and waste and deliver $R \& D$ at costs lower than has been observed for vaccine development under a commercial model. It has for long been considered

\footnotetext{
${ }^{30}$ DNDi (2014), MMV (1999).

${ }^{31}$ DNDi (2014).

${ }^{32}$ CEPI (2017-2021).

${ }^{33}$ Pagliusi et al. (2017).

${ }^{34}$ Ibid.

${ }^{35}$ Ravi and Adalja (2017).

${ }^{36} \mathrm{CEPI}$ (n 32).
} 
that the public sector's role in R\&D is primarily in preclinical research and earlystage discovery, and that know-how, resources and skills to translate these findings to biomedical products are the prerogative of private innovators. However, publicprivate partnerships (PPPs) established to address the market failure for neglected diseases have demonstrated otherwise. For example, between 2003 and 2016, DNDi drove R\&D and marketing approval of six drugs targeting neglected diseases (sleeping sickness, malaria, Chagas's disease, and kala-azar), and has estimated that on average it can develop drugs for between $\$ 110$ million and $\$ 170$ million. ${ }^{37}$ This is around one tenth of the average cost of developing a drug according to estimates based on proprietary data from pharmaceutical companies, though it should be noted that these estimates are controversial. ${ }^{38}$ Another example is the MenAfriVac vaccine against meningitis, which cost $\$ 50$ million to develop-again much lower than the cost usually required to bring a new vaccine to market. ${ }^{39}$

Finally, a third area where CEPI can contribute both intellectually and through action is in advancing the debate on how to maximise public benefits of publiclyfunded research. One specific issue concerns norms guiding decisions to transfer intellectual property and know-how of publicly-funded vaccines and other health technologies to private innovators. A recent example reigniting this debate is the decision by the US Department of Defense to grant an exclusive licence of a Zika vaccine to the pharmaceutical company Sanofi Pasteur. ${ }^{40}$ This vaccine was originally developed with public funding by scientists at the Walter Reed Army Institute of Research. ${ }^{41}$ In this case, the major objection raised by Médecins Sans Frontières (MSF) and other civil society organisations is that the license has been issued without conditions that secure affordability and access to the vaccine. ${ }^{42}$ One concern is that the patent monopol can be abused to charge prices that drive vaccines out of reach for populations who need them. Another concern is that exclusive licensing may unnecessarily delay the entry of competitive suppliers that can manufacture and distribute the vaccine to geographic regions with unmet needs. Finally, exclusive licensing can be a barrier to accessing intellectual property and know-how in order to enhance the characteristics of the vaccine so as to make these more effective in lowresource settings (such as developing more heat-stable versions). Non-governmental organisations, such as MSF and Knowledge Ecology International, have consistently claimed that exclusive licenses are unnecessary, and that the development of vaccines and other publicly funded research could be concluded by public and private actors by sharing the costs of finalising R\&D. ${ }^{43}$

CEPI will operate along the lines of such a model. Governments and philanthropic foundations will originally have financed many promising vaccine candidates CEPI

\footnotetext{
${ }^{37}$ Maxmen (2016).

${ }^{38}$ DiMasi et al. (2016), Maxmen (2016).

${ }^{39}$ WHO (2010).

${ }^{40}$ Doctors Without Borders (2017a).

${ }^{41}$ Barbero et al. (2017).

${ }^{42}$ Doctors Without Borders (2017b).

${ }^{43}$ Doctors Without Borders (2017c), Knowledge Ecology International (2017).
} 
decides to invest in. Public and philanthropic investments channelled through CEPI can move these vaccines from preclinical research and early-stage discovery through phase 1 and phase 2 trials. It is expected that phase 3 trials, too, will be financed by public and philanthropic actors. In these cases, there exist fair arguments for setting conditions for affordability and access at the time when CEPI invests in them, and that these conditions follow the vaccine through its development stages. In some cases, CEPI and other funders could together make a claim for vaccines being priced close to the marginal cost of production.

CEPI's policy on equitable access - approved for a one-year trial period and released in February 2017 after several months of discussions internally as well as with other PDPs, universities, civil society organisations, and private innovators $^{44}$ — considers many of these issues, and sets out a number of guiding principles for managing them. ${ }^{45}$ One key principle is that intellectual property will be managed as a strategic tool to ensure that vaccines are made affordable and available, while maintaining the incentives for private innovators to participate. This is similar to approaches taken by other PDPs. ${ }^{46}$ A second principle is that CEPI, while recognising that an affordable price range may not be possible to determine at an early stage when there are uncertainties around the vaccine development process, still will work with partners to establish a transparent and agreed method for determining the price. This includes considering different sources of information, including information about public and philanthropic contributions to vaccine development costs, cost of goods, expected scale of production, price of existing comparable products, cost of maintaining manufacturing capacity, and procurement agreements. A major concern is ensuring that public and philanthropic investments in $R \& D$ is reflected in the final price of the vaccine. A third principle is that knowledge generated through CEPI's investments should be considered global public goods, and accordingly, CEPI should therefore promote and encourage open access to knowledge and sharing of data in publicly available databases.

More than 80 organisations and over 200 individuals collaborated to create CEPI. ${ }^{47}$ It is expected that CEPI over time will engage with many more public and private actors. DNDi, for example, engaged in over 350 collaborations in 43 states over its first ten years, including over 50 universities and research institutes. ${ }^{48}$ A crucial role played by CEPI is that of an "honest broker", in the form of a neutral, central entity that build trust and foster collaboration between the public and private actors. ${ }^{49}$ Legal and operational independence from collaborating partners and independent decision-making processes will therefore be crucial to act in the interest of its public mission, and to strengthen legitimacy as a global mechanism for

\footnotetext{
${ }^{44}$ It is worth noting that after this chapter was written, CEPI has initiated a process to review and if necessary revise its equitable access policy, based on lessons learned from the one-year trial period.

${ }^{45}$ CEPI (2017).

${ }^{46}$ Kettler and Towse (2002).

${ }^{47}$ Røttingen and others (n 3).

${ }^{48}$ DNDi (n 21).

${ }^{49}$ Goldman (2012).
} 
ensuring global health security. A crucial role will have to be played by national governments - a topic to which we turn next.

\section{CEPI-An Agent for Mobilising Shared Responsibilities for Global Health Security?}

As of September 2017, a group of high-income states-Australia, Belgium, Canada, Germany, Japan, and Norway-have committed to fund CEPI together with the major philanthropic foundations the Wellcome Trust and the Gates Foundation. The European Commission has committed to using its own funding instruments to invest in joint efforts with CEPI. In addition, The Government of India-one of CEPI's founding partners - is finalising its level of commitment.

Most other PDPs and global R\&D organisations have until now relied on financial contributions from OECD states and philanthropic foundations. For example, DNDi's list of public institutional donors includes nine OECD states, and public funding from only two non-OECD states, Brazil and South Africa. ${ }^{50}$ Similarly, MMV lists nine OECD states as funders, and not a single non-OECD state. ${ }^{51}$ UNITAID, which focus on market-interventions to increase access to drugs for HIV/AIDS, malaria and tuberculosis, has broader support, with low- and middle-income countries (LMICs) contributing with financial resources generated by an airline levy. However, analysis of financial streams to UNITAID between 2006 and 2011 has shown that highincome states and the Gates Foundation were responsible for 95.8\% of UNITAID's funding. ${ }^{52}$ The beneficiaries of these initiatives are primarily populations in LMICs, although it can be argued that increasing the availability of treatments for neglected diseases also brings benefits to populations in high-income states. It is, however, not unreasonable to argue that the main motivation for these initiatives has been to meet humanitarian needs in LMICs.

In contrast, CEPI explicitly frames its mission as a shared interest for all states. At present, it may be fair to view CEPI as a step initiated by a smaller group of participants, with the aim of mobilising greater support. ${ }^{53}$ For CEPI to be successful over the longer term, there are several reasons why a vigorous effort to broaden the scope of participation-including mobilising participation from LMICs-will be vital. The first is legitimacy: moving towards greater or full participation strengthens CEPI's legitimacy as global mechanism for joint-decision making. The second is sustainability: greater participation avoids the supply of a global public good from depending on a small group of states, and so avoids the political risks associated with such an arrangement. Increasing the number of states investing in CEPI can have a catalytic effect by incentivising contributions from other states from the same

\footnotetext{
${ }^{50}$ DNDi (2017).

${ }^{51}$ MMV (2017).

${ }^{52}$ Center for Global Development (2013).

${ }^{53}$ Ötker-Robe (n 18).
} 
region. In addition, involving LMICs may avoid CEPI's mission being framed as only a responsibility of bilateral development agencies and official development assistance (ODA), or only a health security issue for high-income states. There are two reasons why the latter may be beneficial. One is to avoid limiting the sources and channels of funding from which CEPI's mission could be financed. The second is that allocating the responsibility for financing CEPI's mission to ODA funds alone can risk diverting resources from other pressing priorities in LMICs. ${ }^{54}$

Broadening the scope of states depends on the willingness of national governments to share the responsibility for investing in a global institutional response. To achieve this objective, a number of factors affecting this willingness needs to be addressed. First of all, CEPI will—similarly to other international institutions set up to address global public goods - face the temptation of states to freeride on the contributions of others. If a small group of states invests in CEPI to develop vaccines, other states may benefit from the prevention of epidemics without incurring any costs. Some proposals for overcoming collective action failures, such as the club mechanism for climate change proposed by William Nordhaus, argue in favour of a voluntary group to cooperate to derive mutual benefits from sharing the costs of producing a global public good, and that non-participants are penalised in the form of trade or financial sanctions. ${ }^{55}$ However, most proposals operate with voluntary participation as a precondition for cooperation between sovereign actors, and CEPI too follows this path. The large number of environmental treaties negotiated by the UN system indicates willingness on part of sovereign states to share the costs of international cooperation.

Remote and uncertain benefits generate another prominent factor explaining why willingness may be low. This is especially a challenge for CEPI. Investing in vaccines against EIDs is, with a few exceptions, a matter of mitigating future risks. We do not know when the next epidemic will strike, and if vaccines developed through CEPI's investments actually will be put to use. In addition, the burden of disease directly attributable to EID outbreaks is low. Many other health challenges-child and maternal health, HIV/AIDS, and non-communicable diseases-cause continuous concern to policymakers and health professionals in all states. Politicians may therefore be unwilling to prioritise upfront expenditures to address uncertain future risks amidst other pressing challenges, especially if there are political risks associated with redirecting resources. Yet studies of previous epidemics suggest that the disruptive effect of epidemics on communities and states leads to total costs that exceed the cost of mitigation. In addition, the health impact of an outbreak may go well beyond the burden of disease directly attributable to the actual pathogen (Box 4). In their assessment of the international response to the Ebola outbreak, Save the Children identified the amount committed by external donors to fight Ebola in Sierra Leone, Guinea, and Liberia to be fifteen times the annual national health budgets of the three states combined, and three times the cost of ensuring essential

\footnotetext{
${ }^{54}$ Guillamount (2002).

${ }^{55}$ Nordhaus (2015).
} 
healthcare for the populations in these states ${ }^{56}$ Overall, there is sound evidence for investing in epidemic preparedness to prevent future risks, and accordingly, CEPI has been framed as an insurance policy to protect against the human and financial risks of future epidemics. ${ }^{57}$

The concern for equity bolsters the case for making upfront investments. Mortality and morbidity from epidemics and pandemics tend to be distributed unequally, both between states (as observed for Ebola and Zika), and within states, including highincome states. ${ }^{58}$

\section{Box 4. Disruption, aversion behaviour and the economic and health impact of the 2014-15 West African Ebola outbreak}

In the context of an epidemic, aversion behaviour refers to behaviour resulting from the fear of being exposed to the pathogen. Reduced economic activity, cautious investors, and closure of businesses may be the result of individuals avoiding exposure to the disease. Governments often also exercise aversion behaviour by overestimating risks and imposing unwarranted restrictions on travel and trade. The World Bank estimated the foregone short-term economic output in 2014 due to Ebola in Guinea, Liberia, and Sierra Leone to be over US $\$ 300$ million. The cost of health care, forgone productivity of people directly affected by the epidemic, and the behaviour of other actors-such as trading partners-were suggested to be the main explanatory factors. The loss in GDP in 2015 was estimated to be US\$1.6 billion in the three most affected states. Neighbouring states, too, were reported by the World Bank to experience adverse economic impacts of the epidemic. Moreover, the disease can cause disruption of health care systems - often in already fragile and low-resourced settings - and reduce access to diagnostic services and treatments for other healthcare conditions in affected areas. Modelling based on cross-sectional surveys, interviews, and malaria indicators between 2011 and 2014 suggested that Ebola-affected areas observed a greater number of malaria deaths. The same areas also observed growing risk of outbreaks of vaccine-preventable diseases such as measles and pertussis due to childhood vaccinations being disrupted during the Ebola outbreak. Studies have also observed 20\% nationwide drop in in-hospital deliveries and C-sections during the Ebola outbreak, indicating a likely indirect impact of the epidemic on maternal mortality.

In addition, a case for CEPI can be made from intergenerational equity - a general concept of fairness between generations, which frequently has been invoked in response to climate change and environmental degradation to argue that the present

\footnotetext{
${ }^{56}$ Save the Children (2015).

${ }^{57}$ Yamey et al. (2017); Brende and others (n 5).

${ }^{58}$ Mamelund (2006), Grantz et al. (2016).
} 
generation has a moral responsibility for protecting future generations from disproportionately experiencing the harmful consequences. ${ }^{59}$ Invoking the concept for epidemic preparedness and protection against infectious diseases would make the case that present generation has benefited from vaccines developed by the previous generation, and accordingly, the present generation should do the same for future generations. Moreover, since vaccine development takes a long time, and the present generation has experienced the consequences of outbreaks and acquired knowledge about the value of vaccines in preventing such outbreaks, the present generation should be compelled to invest today for the sake of preventing human suffering in the future.

Even when the costs and benefits of mitigating a future risk is well understood, uncertainty about the benefits of the proposed policy response, namely cooperation through an international institution, may be a factor impeding collective action. ${ }^{60}$ CEPI will therefore have to make a convincing case to states that the benefits of investing in R\&D together, and entrusting CEPI with the authority to manage and allocate these resources will yield more benefit and be less costly than investments made by states on their own. The benefits will have to be clearly and quickly demonstrated in the form of vaccines developed and stockpiled over the next five years, and contributions to an effective response if a pathogen targeted by CEPI becomes the cause of an epidemic.

CEPI must also ensure that its decision-making processes are fair and that it grants all investors as well as other states at high risk of epidemics an effective voice, and truly represents an instrument for joint decision-making. ${ }^{61}$ CEPI may gain over the longer term from early and active involvement of states that have not yet invested in its mission, since participation may increase exchange of information about the benefits of cooperation, and over time incentivise contributions from non-participants. To this end, CEPI's governance bodies are composed of not only representatives from states that have committed financially during its establishment, but also have allocated seats for states that will be crucial for local manufacturing, surveillance, implementing clinical trials, and other areas of R\&D preparedness and response. On an operational level, CEPI is also engaging with the states that are likely to be most affected by outbreaks of the prioritised diseases, and has sought input on how to improve vaccine development projects giving due consideration to implementation, engagement, and partnership needs in affected states.

The factors described above can be considered equally relevant for all states. Two additional factors are important for CEPI consider with respect to participation from LMICs. One is the ability to demonstrate that CEPI's mission is fully aligned with the interests and priorities of LMICs, and not driven by the interests of high-income states. A danger with the concept of "global health security" is that, instead of being associated with a concern for the collective security of people across all nations, it is understood as an agenda prioritising interventions (such as vaccines) to protect

\footnotetext{
${ }^{59}$ Beckerman (1997).

${ }^{60}$ Ötker-Robe (n 18); Kaul, 'Global Public Goods: Explaining Their Underprovision' (n 8).

${ }^{61}$ Kaul, Global Public Goods (n 18).
} 
high-income states from diseases that emerge from LMICs. ${ }^{62}$ It may therefore be strategically valuable for CEPI to align its notion of global health security with "human security" - a concept placing emphasis on people over states with a particular concern for the most vulnerable populations. ${ }^{63}$ There may also be a concern that an emphasis on vaccines alone displaces attention and resources from strengthening public health capacities, general health services, and the push towards universal health coverage. While it is not part of CEPI's mission to engage in these areas, CEPI can still contribute to strengthening capacity for vaccine development, testing and manufacturing in LMICs. For LMICs, efforts that boost technical know-how and vaccine manufacturing capacity reduce the dependence and vulnerability of relying on multinational manufacturers for availability and accessibility of vaccines. Moreover, increasing vaccine manufacturing capacity in LMICs contributes towards increasing overall global production capacity in the event of a future epidemic or pandemic. When different partnership models were reviewed prior to the establishment of CEPI, it was noted that achieving equitable distribution of benefits would require broadening the base of vaccine manufacturers across LMICs and increasing their capacity for scale-up manufacturing, including implementing appropriate arrangements for technology transfer. CEPI has publicly signalled an intent to work with LMICs and to be a mechanism for transfer of knowledge and expertise for strengthening capacity for vaccine development and testing. ${ }^{64}$ CEPI has also actively engaged with the DCVMN, including being present at their annual general meeting in $2016 .{ }^{65}$ Moreover, CEPI's policy on securing equitable access to vaccines stipulates that CEPI will seek to reach agreement on arrangements up-front for sub-licensing intellectual property related to the vaccine candidate and accessing know-how, trade secrets and other undisclosed knowledge in order to achieve equitable access obligations. ${ }^{66} \mathrm{At}$ the time of writing, CEPI has not more specifically described how it will move forward with respect to setting up technology transfer arrangements. It is expected that arrangements will develop over time as CEPI gains experience negotiating individual contracts with its grantees.

To inform such arrangements, experience from previous models for technology transfer of vaccine technologies is worth noting. ${ }^{67}$ The International Technology Platform for Influenza Vaccines was established in 2008 with support from WHO and hosted by the Netherlands Vaccine Institute both to provide training in influenza vaccine development and manufacturing to inexperienced grantees from LMICs, and to facilitate technology transfer. ${ }^{68}$ The hub was set up as part of implementing the 2006 WHO Global Action Plan for Influenza Vaccines, which included the objective

\footnotetext{
${ }^{62}$ Rushton (2011).

${ }^{63}$ Labonté (2014).

${ }^{64}$ Hatchett (2017).

${ }^{65}$ Pagliusi et al. (2017).

${ }^{66}$ CEPI (2017).

${ }^{67} \mathrm{WHO}(2011)$.

${ }^{68}$ Hendriks et al. (2011), Grohmann et al. (2016).
} 
of transferring influenza vaccine production technology to manufacturers and governments in LMIC in order to reduce the overreliance of vaccine manufacturers in high-income states, and strengthen the capacity needed to protect the global population in the event of a pandemic. CEPI is unlikely to hold similar levels of in-house capacity needed to serve as a technology transfer "hub" by its own, but could pool the knowledge and expertise on vaccine-related technologies and processes of its coalition partners.

Two other models could also be explored. The first would involve CEPI being a facilitator for technology transfer, similar to how WHO and PATH facilitated technology transfer through funding and technical support to Serum Institute of India to develop the MenAfriVac vaccine. ${ }^{69}$ The second would involve setting up shared technology platforms where the facilitating entity involves a range of partners to facilitate technology transfer to multiple recipients. Such a platform was set up by PATH to facilitate technology transfer to vaccine manufacturers from Brazil, China, and India for developing new rotavirus vaccines. ${ }^{70}$ Finally, it is worth noting that technology transfer should not be seen as something occurring solely between donors in high-income states and recipients in LMICs. With increasing capacity for vaccine R\&D and manufacturing among LMICs, CEPI could facilitate technology transfers between these states to strengthen epidemic preparedness globally.

A second important factor for mobilising participation from LMICs is to ensure that the benefits of investing in CEPI are equitably shared. Participation may be affected negatively if it has not been duly considered how to secure equitable benefit sharing among states. A telling example is the global influenza network system that operated under the WHO. In 2007, Indonesia objected to sharing virus samples of avian flu and cooperating with the international network, arguing that insufficient attention had been paid to equitable access to the benefits of cooperating (Box 5). ${ }^{71}$ As already described, CEPI has paid attention to a number of crucial issues that address concerns for access to vaccines and data sharing.

\section{Box 5. The Pandemic Influenza Preparedness framework: sharing the benefits of international cooperation}

An example of a case where the lack of specific mechanisms for benefit-sharing acted as a disincentive to international cooperation is the Global Influenza Surveillance and Response System (GISR, formerly known as the Global Influenza Surveillance Network) coordinated by the WHO. The objectives of this network are to characterise influenza viruses circulating in humans globally, to monitor the evolution of influenza viruses, and to detect and obtain isolates of new influenza viruses infecting humans, paying special attention to

\footnotetext{
${ }^{69}$ Tiffay et al. (2015).

${ }^{70}$ Préaud (2010).

${ }^{71}$ Fidler and Gostin (2011).
} 
viruses with pandemic potential. Through this system, many low- and middleincome states had been sharing influenza viruses with designated laboratories in the US, Australia, the UK, and Japan. It became known that these laboratories had shared viruses with private companies in order for these to develop vaccines without the permission from the states that had provided the samples. The crux of the problem was that these vaccines were later sold at prices unaffordable to many low- and middle-income states. As a consequence, LMICs questioned why they should contribute to sample sharing if their own populations weren't secured access to the benefits of sharing viruses - that is, vaccines at an affordable price. During the emergence of avian influenza (also known as influenza A virus subtype H5N1), Indonesia took the step of not sharing virus specimens with the WHO, and called for greater equity and access to the benefits of sharing influenza viruses with the international network. In response to these concerns and after multilateral negotiations, a new framework for sharing viruses and access to vaccines, the Pandemic Influenza Preparedness (PIP) framework, was established. The framework seeks to ensure that all states benefit equally from sharing influenza virus specimens. In addition, $50 \%$ of the running costs of the WHO GISR are covered by influenza vaccine manufacturers that benefit from the use of WHO's surveillance and response network.

While full participation of states may be the long-term objective, it may be unreasonable to expect this over the short term. A meaningful exercise is therefore to consider whether some states should carry a greater responsibility for investing in CEPI, and what norms should guide such contributions. Criteria and norms to guide contributions are relatively underexplored in the field of global public goods in general and global public goods for health in particular. A useful starting point for advancing this discussion is to draw upon insight from the rich literature specifying ethical principles for informing burden- and benefit-sharing arrangements for mitigation and adaptation to climate change. ${ }^{72}$ It may particularly be useful to examine the application of the principle of "common but differentiated responsibilities" (CBDR) (Box 6), the burden-sharing norms that follow from this principle, and the appropriateness of these norms to CEPI's mission. ${ }^{73}$

\section{Box 6. Common but differentiated responsibilities}

The principle of CBDR was formalised in international environmental law at the United Nations Conference on Environment and Development in 1992. When the principle was originally devised, the burden-sharing framework that followed apportioned limited responsibility to low- and middle-income states, most notably observed by the differentiation between the high-income states

\footnotetext{
${ }^{72}$ Ringius et al. (2002), Méjean et al. (2015), Page (2008).

${ }^{73}$ Pauw et al. (2014).
} 
listed as "Annex 1" parties, and the LMICs listed as "non-Annex 1" parties. This was mainly due to the emphasis placed on the historical contribution to the problem. The proffered justification for differentiating responsibilities this way was that high-income states both contributed more greatly to the problem and benefited economically from higher levels of greenhouse gas emissions in the past, and therefore should bear greater responsibility for addressing the problem. Over time, and with the economic growth and increasing levels of greenhouse gas emissions in LMICs (particularly in China and India), it has become clear that mitigation efforts by high-income states alone will be insufficient to reach global targets, and recent attempts have therefore been made to identify how CBDR can become a more meaningful guiding principle for global climate change agreements. The recent Paris Agreement recognises the principle of CBDR and that high-income states must continue to take the lead in mitigating climate change, but for the first time establishes that all states have the obligation to contribute to mitigating and adapting to climate change.

In connection with climate change, the principle of CBDR recognises two dimensions of the challenge. The first is that the challenge is of concern to all states, and accordingly, the "widest possible cooperation by all states is needed to combat climate change and the adverse effects thereof". ${ }^{74}$ The second is that responsibility for addressing this shared challenge should be "differentiated"; that is, some states should bear greater responsibility due to differences in historical contribution to the problem, ability to address the problem, and specific development needs. Global drivers for future epidemics include climate change, international travel, population growth, and urbanisation. ${ }^{75}$ The extent to which states contribute to these drivers differ; for the sake of argument, it will be assumed that future epidemics cannot be attributed directly to any form of historical activity by states. We can therefore concentrate on the latter two aspects, which offer more relevant inputs to a potential burden-sharing framework for epidemic preparedness.

An alternative way of thinking about the ability to address the problem is to translate it into a principle of "capacity to pay", which implies two things: firstly, that all states should be considered as potential contributors, but that richer states should pay to address the common challenge based on a principle of solidarity; and secondly, that no state should bear unacceptably high costs, thereby indicating the need to broaden the base of contributors in order to share responsibilities. ${ }^{76}$ The second aspect - a concern for development needs - is also relevant to consider in the context of R\&D preparedness. LMICs face many pressing challenges which needs to be taken into account, and perhaps adjusted for, when clarifying the expectation for contributions from these states.

\footnotetext{
${ }^{74}$ Ibid.

${ }^{75}$ Bloom et al. (2017).

${ }^{76}$ Ibid., Dellink et al. (2009).
} 
Calls for shared responsibility have also been made in relation to financing of global health R\&D. Most notably, the WHO Consultative Expert Working Group (CEWG) on Research and Development concluded in 2012 that all states should commit at least $0.01 \%$ of GDP on government-funded health technology-related R\&D to meet the specific health needs of LMICs. ${ }^{77}$ Relevant to the context of CEPI are the three main arguments that formed the basis of this recommendation. The first was that R\&D to meet neglected health needs is not "just a responsibility of development aid or indeed donors", but that there is a need to "reframe the issue away from development assistance". ${ }^{78}$ Accordingly, the same target was set for states from all income groups. The second was that R\&D efforts should be related to GDP, since this represents the best available measure of ability to pay. The target $-0.01 \%$ of GDP - was set to increase total public sector R\&D spending on health needs of LMICs to US\$ 6 billion globally, which at the time would be $0.01 \%$ of global GDP.

The CEWG, while calling for participation from all states, did not examine different criteria that indicate the ability to pay in detail, nor how these criteria should relate to other considerations, such as health and development needs. For this purpose, it may be useful to consider contributions from the recent literature examining allocation criteria and contribution norms for financial resources and in-kind contributions for activities aimed at improving health in low- and middle-income states, also known as development assistance for health (DAH). ${ }^{79}$ Allocation and eligibility criteria that guide the allocation of DAH are focused on states, and attempt to establish which states have the greatest need for DAH and in which states the allocation of DAH will yield the greatest developmental gains. In the context of CEPI and global public goods, the beneficiaries are not individual states, but the global population. Considering allocation criteria in the same way is therefore not relevant.

With respect to contribution norms, two broad categories may be considered: benefit-related norms, and capacity-related norms. ${ }^{80}$ Benefit-related norms indicate that contributions should increase according to the extent to which the contributor benefits from investing in the specific arrangement. The WHO has developed a priority list of EIDs with potential to generate a public health emergency, and for which insufficient or no preventive or curative solutions exist. The latest list, updated in February 2018, includes priority diseases where low- and middle-income states will carry the greatest risk of outbreaks and a disproportionately heavy disease burden, as well as economic burden. ${ }^{81}$ Accordingly, these states stand to benefit the most from vaccines against EIDs (assuming that these are available and accessible to populations regardless of ability to pay). Thus, benefit-related norms strengthen the case for contributions from LMICs. However, benefit-related norms must be considered together with capacity-related norms.

\footnotetext{
${ }^{77}$ Røttingen and Chamas (2012).

${ }^{78}$ WHO (2012).

${ }^{79}$ Ottersen et al. (2014, 2017).

${ }^{80}$ Ottersen and others (n 79).

${ }^{81}$ WHO (2017a).
} 
The main capacity-related norm that may guide contributions to DAH, and plausibly also global public goods, is gross national income per capita (GNIpc), where higher GNIpc indicate greater capacity to contribute. In connection with DAH, this criterion has been interpreted as an indicator for the domestic capacity to address health needs without external support. ${ }^{82}$ Many low-income states have limited domestic capacity and large health needs for which they rely on external support. Moon has estimated that DAH comprised $31.7 \%$ of total health spending in low-income states in 2013 , compared with $3.1 \%$ in lower-middle-income states, and $0.3 \%$ in upper-middle-income states. ${ }^{83}$ It may therefore be fair not to expect contributions from low-income states over the short term, but rather expect increased domestic financing to strengthen things like laboratory capacity, surveillance, and other core public health capacities - efforts which also contribute to global health security and CEPI's mission of preventing the spread of epidemics.

Therefore, and in tune with the emerging literature debating the role of middleincome countries (MICs) as funders and/or recipients of DAH, we may focus on the role of these states as potential contributors. ${ }^{84}$ According to the World Bank classification, and at the time of writing, there are 108 middle-income states. For many MICs, their mid-level GNIpc indicates some internal capacity to respond to domestic health needs. However, many MICs have also large unmet health needs (almost $70 \%$ of the global disease burden), are home to a large proportion of the people living in poverty (over 75\%), and have large inequalities in health between income groups. In the context of CEPI and epidemic preparedness, the crux of the matter is to consider whether it is reasonable that these states are called upon to pull weight for vaccine development to secure global health security, or whether it is reasonable that their resources are fully devoted to ensuring priority health services for their own populations first. It here paramount to recognise that MICs represent a heterogeneous group of states which differ widely in capacity to pay and health needs. A starting point for identifying states that should contribute financially to epidemic preparedness can therefore be to identify those states with a GNIpc which indicate ineligibility for DAH. In the case of DAH, it has been argued that a transition zone is needed whereby states gradually move from being ineligible for DAH to becoming funders. ${ }^{85}$ This may equally apply to the identification of funders for epidemic preparedness (and other global public goods). The major reason for why such a transition zone can be useful is that one may want to consider mobilising financing only from states with domestic capacity to ensure priority health services for their populations. ${ }^{86}$ Directing resources towards CEPI's mission should not introduce harms or impede progress on other areas, referring back to the discussion about how CEPI's mission to strengthen global health security should avoid impeding broader efforts to strengthen general health services, but instead should reinforce these efforts.

\footnotetext{
${ }^{82}$ Ottersen, Moon and Røttingen (n 79).

${ }^{83}$ Moon et al. (2017b).

${ }^{84}$ Ottersen, Moon and Røttingen (n 79); Verbeke and Renard (2011).

${ }^{85}$ Ottersen, Moon and Røttingen (n 79).

${ }^{86}$ Ibid.
} 
Overall, a provisional conclusion may be that CEPI over the short term should expect contributions from high-income states and most upper middle-income states. A strategic choice to be made is whether or not CEPI should operate with an inclusion threshold, above which states should be expected to invest in CEPI's mission. A source of arguments for there being no threshold is maintenance of a focus on CEPI's mission being a shared responsibility for all states.

Moreover, an inclusion threshold based on GNIpc alone will not precisely reflect the significant contributions specific states below a threshold could make, and the benefits these states could get in return. The Government of India is among CEPI's founding members and is expected to contribute financially to CEPI's mission. India's GNIpc of US $\$ 1570$ in 2015 corresponds to a classification as a lower-middle-income state, placing it well below thresholds that identify upper-middle-income states as funders of DAH. ${ }^{87}$ However, India is also an economic powerhouse and emerging donor of development assistance. ${ }^{88}$ Through its vaccine industry, India has a significant impact on the global vaccine market, including leading the development of vaccines for meningitis and rotavirus. ${ }^{89}$ In addition to financial contributions, India is therefore well positioned to make significant non-financial contributions through the transfer of knowledge and R\&D capabilities. India could also expect to benefit domestically, both through the involvement of its vaccine industry, and through the development of vaccines that meet its own public health needs, for example vaccines that protect against Chingunkunya - a virus which caused a large outbreak in New Delhi in 2016. ${ }^{90}$ India's investment in CEPI could operate as a benchmark against with other states with similar and higher levels of GNIpc may consider their own contributions.

Finally, a crucial part of discussing whether CEPI can represent a legitimate global response to a shared challenge is discussing how CEPI fits into the broader global health architecture, and above all, how it will relate to the WHO. Similarly to the critique of other global health initiates, it may be argued that CEPI, voluntarily funded by a small group of donor states to focus on a specific problem in global health, draws attention away from strengthening poorly resourced health systems. ${ }^{91}$ Moreover, it may be argued that establishing a new institution to strengthen epidemic preparedness challenges the central role of WHO as the world's directing and coordinating authority for health.

Some arguments can be made in defence of CEPI. Historically, the WHO has had a limited role in the financing $R \& D$, but it has played a crucial role as a convenor of partnerships to address underprioritised health needs. Two examples have already been mentioned: the MenAfriVac and Ebola vaccines, where WHO played crucial roles. ${ }^{92}$ Another example is the Special Programme for Research and Training in

\footnotetext{
${ }^{87}$ Ibid.

${ }^{88}$ Piccio (2014).

${ }^{89}$ Kaddar et al. (2014), Bhan et al. (2014).

${ }^{90}$ Donald (2016).

${ }^{91}$ Clinton and Sridhar (2017).

${ }^{92}$ Tiffay and others (n 69).
} 
Tropical Diseases (TDR), which is hosted by WHO (and sponsored by the United Nations Children's Fund (UNICEF), the United Nations Development Programme (UNDP), and the World Bank). ${ }^{93}$

The WHO was closely involved in the establishment of CEPI. The idea of establishing CEPI came, among other processes, out of a consultation meeting on the financing work stream of a WHO process to develop a R\&D blueprint for action to prevent epidemics. ${ }^{94}$ To ensure a sustained strong relationship between CEPI and WHO, a memorandum of understanding (MoU) was developed and approved by both institutions to clarify the respective roles of each institutions. ${ }^{95}$ Importantly, it is expected that CEPI will rely on and be responsive to the WHO's normative functions and leadership, for example on norms for data and sample sharing, liability, and scientifically sound and ethically acceptable clinical trial designs. WHO and its member states have prioritised the issue of $R \& D$ against EIDs by approving the R\&D blueprint for action to prevent epidemics at the World Health Assembly in 2016. ${ }^{96}$ CEPI can therefore also be viewed as an implementation mechanism through which states may act on a priority set by the multilateral system.

\section{Conclusion}

In this chapter, we have explained the rationale for establishing a new global health institution to generate the global public good of preventing future epidemics from becoming humanitarian crises. CEPI can be considered to add to an evolving global institutional framework for international cooperation to address shared challenges. It is being established at a time when various forms of international cooperation and agreements is facing greater uncertainty. It is therefore crucial that CEPI manages the trust placed in it by demonstrating the value of investing together to address a shared challenge. Over the next 5-10 years, it is hoped that CEPI will have successfully demonstrated to governments, private actors, and civil society organisations that collective action is the preferred strategy for preventing future epidemics and strengthening global health security.

\section{References}

Attaran A, Nickerson JW (2014) Is Canada patent deal obstructing Ebola vaccine development? Lancet 384:e61 (London, England)

\footnotetext{
${ }^{93}$ Ridley and Fletcher (2008).

${ }^{94}$ WHO (2016, 2017b).

${ }^{95}$ Memorandum of Understanding between the World Health Organisation and the Coalition for Epidemic Preparedness Innovations (2017).

${ }^{96}$ WHO, 'An R\&D Blueprint for Action to Prevent Epidemics. Plan of Action.' (n 94).
} 
Barbero CJ et al (2017) Zika virus purification. Google Patents. https://encrypted.google.com/ patents/WO2017109227A1?cl=pt

Beckerman W (1997) Debate: intergenerational equity and the environment. J Polit Phil 5:392

Bhan MK et al (2014) Team science and the creation of a novel rotavirus vaccine in India: a new framework for vaccine development. Lancet 383:2180 (London, England)

Bixler SL, Duplantier AJ, Bavari S (2017) Discovering drugs for the treatment of Ebola virus. Curr Treat Opt Infect Dis 9:299

Bloom DE, Black S, Rappuoli R (2017) Emerging infectious diseases: a proactive approach. Proc Natl Acad Sci U S A 114:4055

Brende B et al (2017) CEPI-a new global R\&D organisation for epidemic preparedness and response. Lancet 389:233 (London, England)

CDC (2016) Sierra Leone trial to introduce a vaccine against Ebola (STRIVE) Q\&A, 20 Apr 2016. https://www.cdc.gov/vhf/ebola/strive/qa.html. Accessed 10 Oct 2017

CDC (2017) Outbreaks chronology: Ebola virus disease. https://www.cdc.gov/vhf/ebola/outbreaks/ history/chronology.html

Center for Global Development (2013) UNITAID. Background paper prepared for the working group on value for money: an agenda for global health funding agencies. https://www.cgdev.org/ doc/Silverman_UNITAID_Background.pdf

CEPI (2017-2021) Preliminary Business Plan 2017-2021. http://cepi.net/sites/default/files/CEPI\% 20Preliminary\%20Business\%20Plan\%20011116.pdf

CEPI (2017) CEPI policy documentation. http://cepi.net/sites/default/files/CEPI\%20Policy\% 20Documentation.pdf

Clinton C, Sridhar D (2017) Who pays for cooperation in global health? A comparative analysis of WHO, the World Bank, the global fund to fight HIV/AIDS, Tuberculosis and Malaria, and Gavi, the vaccine alliance. Lancet (London, England)

Commission on a Global Health Risk Framework for the Future (2016) The neglected dimension of global security: a framework to counter infectious disease crises. http://nam.edu/GHRFreport. Accessed 1 Feb 2016

Dellink R et al (2009) Sharing the burden of financing adaptation to climate change. Glob Environ Change 19:411

DiMasi JA, Grabowski HG, Hansen RW (2016) Innovation in the pharmaceutical industry: new estimates of R\&D costs. J Health Econ 47:20

DNDi (2014) An innovative approach to $R \& D$ for neglected patients ten years of experience \& lessons learned by DNDi. https://www.dndi.org/wp-content/uploads/2009/03/DNDi_ Modelpaper_2013.pdf

DNDi (2017) Donors. https://www.dndi.org/donors/donors/. Accessed 10 May 2017

Doctors Without Borders (2017a) US department of defense announces decision to give pharmaceutical corporation exclusive rights on taxpayer-funded Zika vaccine, failing to ensure affordable and sustainable access. http://www.doctorswithoutborders.org/article/us-departmentdefense-announces-decision-give-pharmaceutical-corporation-exclusive-rights

Doctors Without Borders (2017b) Appeal to the department of defense decision to grant an exclusive license for U.S. Government-Owned Patents on Zika Vaccine Candidate. https://www. doctorswithoutborders.org/sites/usa/files/appeal_dod_zika_vaccine_may_19.pdf

Doctors Without Borders (2017c) Doctors without borders/Médecins Sans Frontières (MSF) comments to the department of defense notice of grant intent to an exclusive license of U.S. government-owned patents on Zika vaccine. https://www.doctorswithoutborders.org/sites/usa/ files/msf_comments_to_fr_notice_re_zika_vaccine_candidate_licensing.pdf

Donald C (2016) Delhi has been hit by a Chikungunya epidemic — what is this disease? The conversation, 19 Sept 2016. https://theconversation.com/delhi-has-been-hit-by-a-chikungunya-epidemicwhat-is-this-disease-65592. Accessed 10 Oct 2017

Fidler DP, Gostin LO (2011) The WHO pandemic influenza preparedness framework: a milestone in global governance for health. JAMA 306:200 
Folayan MO et al (2016) Ebola vaccine development plan: ethics, concerns and proposed measures. BMC Med Ethics 17:10

Goldman M (2012) Public-private partnerships need honest brokering. Nat Med 18:341

Gostin LO et al (2016) Toward a common secure future: four global commissions in the wake of Ebola. PLoS Med 13:e1002042

Grantz KH et al (2016) Disparities in influenza mortality and transmission related to sociodemographic factors within Chicago in the pandemic of 1918. Proc Natl Acad Sci U S A 113:13839

Grohmann G et al (2016) Challenges and successes for the grantees and the technical advisory group of WHO's influenza vaccine technology transfer initiative. Vaccine 34:5420

Guillamount P (2002) Linkages between official development assistance and global public goods. https://pdfs.semanticscholar.org/d8ab/e2b314b7f15b118ca55deb3b15e304fcfec5.pdf. Accessed 13 May 2017

Hatchett R (2017) Op-Ed: Africa needs an insurance policy against future epidemics. CNBC Africa. https://www.cnbcafrica.com/insights/world-economic-forum/wef-africa-2017/2017/05/ 05/africa-vaccines/. Accessed 5 Oct 2017

Hendriks $\mathrm{J}$ et al (2011) An international technology platform for influenza vaccines. Vaccine 29(Suppl 1):A8

Jones SM et al (2005) Live attenuated recombinant vaccine protects nonhuman primates against Ebola and Marburg viruses. Nat Med 11:786

Kaddar M, Milstien J, Schmitt S (2014) Impact of BRICS' investment in vaccine development on the global vaccine market. Bull World Health Organ 92:436

Kamradt-Scott A (2016) WHO's to Blame? The World Health Organisation and the 2014 Ebola Outbreak in West Africa. Third World Q 37:401

Kaul I (2012) Global public goods: explaining their underprovision. J Int Econ Law 15:729

Kaul I (2013) Global public goods: a concept for framing the post-2015 Agenda? Dt Inst für Entwicklungspolitik

Kennedy SB et al (2016) Implementation of an Ebola virus disease vaccine clinical trial during the Ebola epidemic in Liberia: design, procedures, and challenges. Clin Trials 13:49 (London, England)

Kettler H, Towse A (2002) Public private partnerships for research and development: medicines and vaccines for diseases of poverty. Office of Health Economics. https://www.ohe.org/ publications/public-private-partnerships-research-and-development-medicines-and-vaccinesdiseases. Accessed 13 May 2017

Knowledge Ecology International (2017) KEI/MSF comments to NIH on licensing of patents on attenuated respiratory syncytial virus (RSV) vaccines. https://www.keionline.org/node/2445. Accessed 1 Oct 2017

Kremer M, Glennerster R (2016) Strong medicine. Creating incentives for pharmaceutical research on neglected diseases. Princeton University Press, Princeton

Labonté R (2014) Health in all (foreign) policy: challenges in achieving coherence. Health Promot Int 29(Suppl 1):i48

Mamelund S-E (2006) A socially neutral disease? Individual social class, household wealth and mortality from Spanish Influenza in two socially contrasting parishes in Kristiania 1918-19. Soc Sci Med 62:923

Marzi A, Feldmann H (2014) Ebola virus vaccines: an overview of current approaches. Expert Rev Vaccines 13:521

Maxmen A (2016) Busting the billion-dollar myth: how to slash the cost of drug development. Nature 536:388

Méjean A, Lecocq F, Mulugetta Y (2015) Equity, burden sharing and development pathways: reframing international climate negotiations. Int Environ Agreem Polit Law Econom 15:387

Memorandum of Understanding between the World Health Organisation and the Coalition for Epidemic Preparedness Innovations. http://www.dcvmn.org/IMG/pdf/mou_cepi_-_who.pdf. Accessed 10 Oct 2017 
MMV (2017) Our donors. https://www.mmv.org/partnering/our-donors. Accessed 10 May 2017

MMV: New Medicines for Malaria Venture (1999) TDR News 2

Moon S et al (2017a) Post-Ebola Reforms: ample analysis, inadequate action. BMJ (Clin Res ed) 356:j280

Moon S, Røttingen J-A, Frenk J (2017b) Global public goods for health: weaknesses and opportunities in the global health system. Health Econ Policy Law 12:195

Morrissey O, te Velde DW, Hewitt A (2002) Defining international public goods. In: Ferroni M, Mody A (eds) International public goods: incentives, measurement, and financing. Springer, Berlin. https://doi.org/10.1007/978-1-4615-0979-0_2

Nordhaus W (2015) Climate clubs: overcoming free-riding in international climate policy. Am Econ Rev 105:1339

Offit PA (2005) Why are pharmaceutical companies gradually abandoning vaccines? Health Affairs (Proj Hope) 24:622

Ötker-Robe İ (2014) Global risks and collective action failures: what can the international community do? IMF Working Paper. International Monetary Fund

Ottersen $T$ et al (2014) Development assistance for health: quantitative allocation criteria and contribution norms. The Royal Institute of International Affairs. https://www.chathamhouse.org/sites/files/chathamhouse/field/field_document/ 20140901DevelopmentAssistanceHealthQuantitativeOttersenKamathMoonRottingenRevised. pdf. Accessed 13 May 2017

Ottersen T, Moon S, Røttingen J-A (2017) The challenge of middle-income countries to development assistance for health: recipients, funders, both or neither? Health Econ Policy Law 12:265

Page EA (2008) Distributing the burdens of climate change. Environ Polit 17:556

Pagliusi S et al (2017) Vaccines: shaping global health. Vaccine 35:1579

Pauw P et al (eds) (2014) Different perspectives on differentiated responsibilities: a state-of-the-art review of the notion of common but differentiated responsibilities in international negotiations. Dt Inst für Entwicklungspolitik

Perkins MD et al (2017) Diagnostic preparedness for infectious disease outbreaks. Lancet (London, England)

Piccio L (2014) In latest Indian budget, aid spending dwarfs aid receipts, devex, 24 Feb 2014. https:// www.devex.com/news/top-donors-to-india-85708. Accessed 10 Oct 2017

Plotkin SA, Mahmoud AAF, Farrar J (2015) Establishing a global vaccine-development fund. N Engl J Med 373:297

Préaud J-M (2010) ARVAC project: the "enabling platform" model, Nov 2010. http://www.who. int/phi/news/Presentation8.pdf. Accessed 10 Oct 2017

Pronker ES et al (2013) Risk in vaccine research and development quantified. PLoS ONE 8:e57755

Ravi S, Adalja AA (2017) Strengthening the US medical countermeasure enterprise for biological threats. Health Secur 15:12

Ress MA (2013) Global public goods, transnational public goods: some definitions. Knowledge Ecology International. https://www.keionline.org/node/1790. Accessed 6 Oct 2017

Ridley RG, Fletcher ER (2008) Making a difference: 30 years of TDR. Nat Rev Microbiol 6:401

Ringius L, Torvanger A, Underdal A (2002) Burden sharing and fairness principles in international climate policy. Int Environ Agreem 2:1

Røttingen J-A, Chamas C (2012) A new deal for global health R\&D? The recommendations of the consultative expert working group on research and development (CEWG). PLoS Med 9:e1001219

Røttingen J-A, Godal T (2015) Speeding up epidemic emergency response. Science 350:170 (New York, NY)

Røttingen J-A et al (2017) New vaccines against epidemic infectious diseases. NEngl J Med 376:610

Rushton S (2011) Global health security: security for whom? Security from what? Polit Stud 59:779

Samuelson PA (1954) The pure theory of public expenditure. Rev Econ Stat 36:387

Samuelson PA (1955) Diagrammatic exposition of a theory of public expenditure. Rev Econ Stat $37: 350$ 
Save the Children (2015) A wake-up call. Lessons from Ebola for the World's Health Systems. https://www.savethechildren.net/sites/default/files/libraries/WAKE\%20UP\% 20CALL\%20REPORT\%20PDF.pdf. Accessed 5 Oct 2017

Serdobova I, Kieny M-P (2006) Assembling a global vaccine development pipeline for infectious diseases in the developing world. Am J Public Health 96:1554

Tiffay K et al (2015) The evolution of the meningitis vaccine project. Clini Infect Dis Off Publ Infect Dis Soc Am 61(Suppl 5):S396

Verbeke K, Renard R (2011) Development cooperation with middle-income countries. Institute of Development Policy and Management, University of Antwerp. https://ideas.repec.org/p/iob/ wpaper/2011011.html. Accessed 13 May 2011

WHO (2010) Revolutionary new meningitis vaccine set to wipe out deadly epidemics in Africa. http://www.who.int/mediacentre/news/releases/2010/meningitis_20101206/en/

WHO (2011) Increasing access to vaccines through technology transfer and local production. World Health Organisation

WHO (2012) Research and development to meet health needs in developing countries: strengthening global financing and coordination. World Health Organisation

WHO (2016) An R\&D blueprint for action to prevent epidemics. Plan of action. World Health Organisation. http://www.who.int/csr/research-and-development/WHO-R_D-Final10.pdf. Accessed 9 May 2017

WHO (2017a) Annual review of the list of priority diseases for the WHO R\&D blueprint, Jan 2017. http://www.who.int/emergencies/diseases/2018prioritisation-report.pdf?ua=1. Accessed 27 Sept 2018

WHO (2017b) Outcome document: financing of R\&D preparedness and response to epidemic emergencies. http://www.who.int/medicines/ebola-treatment/Outcome.pdf. Accessed 10 Oct 2017

WHO (2017c) Summary of probable SARS cases with onset of illness from 1 November 2002 to 31 July 2003. http://www.who.int/csr/sars/country/table2004_04_21/en/. Accessed 10 Oct 2017

Yamey G et al (2017) Financing of international collective action for epidemic and pandemic preparedness. Lancet Glob Health

Open Access This chapter is licensed under the terms of the Creative Commons Attribution 4.0 International License (http://creativecommons.org/licenses/by/4.0/), which permits use, sharing, adaptation, distribution and reproduction in any medium or format, as long as you give appropriate credit to the original author(s) and the source, provide a link to the Creative Commons license and indicate if changes were made.

The images or other third party material in this chapter are included in the chapter's Creative Commons license, unless indicated otherwise in a credit line to the material. If material is not included in the chapter's Creative Commons license and your intended use is not permitted by statutory regulation or exceeds the permitted use, you will need to obtain permission directly from the copyright holder.

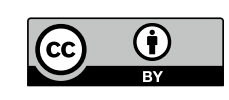

